\title{
Outcomes of mTORi-involving minimized immunosuppression protocols in renal transplantation
}

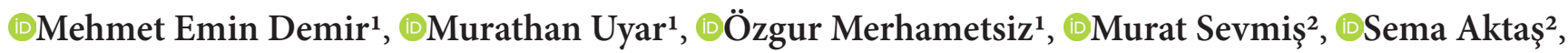 \\ (D)Şinasi Sevmiş² \\ ${ }^{1}$ Yeni Yuzyil University School of Medicine, Deprartment of Nephrology and Organ Transplantation, İstanbul, Turkey \\ ${ }^{2}$ Yeni Yuzyil University School of Medicine, Deprartment of Surgery and Organ Transplantation, İstanbul, Turkey
}

Cite this article as: Demir ME, Uyar M, Merhametsiz Ö, Sevmiş M, Aktaş S, Sevmiş Ş. Outcomes of mTORi-Involving minimized immunosuppression protocols in renal transplantation. J Health Sci Med 2021; 4(1): 71-77.

\begin{abstract}
Aim: Immunosuppression lowering protocols are commonly involving low-dose calcineurin inhibitors (CNIs) and the mammalian target of Rapamycin inhibitor (mTORi). In renal transplant (RT) recipients, due to various factors (the development of polyoma B-K virus $[\mathrm{BKV}]$ and cytomegalovirus [CMV] infections, malignancy, and CNIs nephrotoxicity), immunosuppression lowering comes up mandatory. Here, we present the outcomes of renal allografts after switching from a standard immunosuppression protocol to mTORi-containing lower immunosuppression protocol.

Material and Method: This single-center, retrospective, and observational study includes RTs performed between 2014-2016. Three hundred twenty-two recipients were evaluated and 231 proper recipients were enrolled in the study. Recipients who received mTORi for at least 12 months were included in mTORi arm. Recipients who did not have a BKV and/or CMV screening test, and allograft biopsy were excluded. The remains were enrolled in mTORi-free arm. Allograft survival rate and function before mTORi and at 1, and 3-year under mTORi treatment were compared.

Findings: A total of 231 recipients were followed-up approximately for 5-years. In mTORi arm CMV and BKV viremia positivity rates were higher than mTORi-free group; $\mathrm{p}=0.001$. Additionally, acute rejection (AR) rate was higher in mTORi arm $(\mathrm{p}=0.001)$. Estimated glomerular filtration rate $(\mathrm{eGFR})$ at 1 and 3 -year after mTORi arm was less than mTORi-free arm $(\mathrm{p}=0.001)$. However, 1 and 3 -year recipient and allograft survival rates were similar among two groups; $\mathrm{p}=0.23$ and $\mathrm{p}=0.06$, $\mathrm{p}=0.52$ and $\mathrm{p}=0.72$, respectively.

Conclusion: In renal allograft recipients, mTORi is commonly considered in the cases that require lowering immunosuppression, such as BKV and CMV viremias, and CNI nephrotoxicity. Despite these disadvantages, it may provide a similar allograft survival rate compared to mTORi-free group. However, mTORi use is associated with more AR episodes and may not prevent the development of a worse eGFR.
\end{abstract}

Keywords: mTORi, renal allograft, renal transplantation

\section{INTRODUCTION}

Mammalian target of Rapamycin (mTOR) inhibitors; sirolimus and everolimus, are used in the kidney transplantation to prevent allograft rejection. They exert their effects via inhibiting a signaling pathway executed by mTORCs (mTOR complex 1 and 2) which results in inhibition of the immune response by disruption of the proliferation of $\mathrm{T}$ lymphocytes and induce immune cells apoptosis $(1,2)$.

Calcineurin inhibitors (CNIs) are the most potent drugs in preventing acute allograft rejection in renal transplantation (RTx) recipients. However, CNIs use is associated with acute and chronic allograft dysfunctions (3-5). The majority of immunosuppressant minimizing protocols involve CNI dose reduction and adding mTORi (5-6). Other potential factors that might have negative impacts on allograft functions are cytomegalovirus (CMV) and polyoma BK virus (BKV) infections which are directly or indirectly associated with over immunosuppression (7,8). In CMV and $\mathrm{BKV}$ infections, minimizing immunosuppression is the main approach of the treatment; while mycophenolate mofetil (MMF) is ceased, CNI dose is reduced and mTOR inhibitors are added $(9,10)$. On the other hand, minimizing CNI dose is bearing acute rejection (AR) 
risk, especially when is realized in the first year posttransplant $(11,12)$. Additionally, CNIs-induced acute and chronic allograft nephrotoxicity and malignancy are two other causes that require immunosuppression lowering.

The outcomes of allografts are controversial, in minimized immunosuppression protocols, due to the variability of the study designs. In our study, we present the outcomes of the immunosuppression protocol that consists of low-dose CNI and mTORi, in $\mathrm{RTx}$ recipients.

\section{MATERIAL AND METHOD}

This single-center, retrospective observational study involved all kidney transplant recipients between the years 2014-2016. Data of 507 recipients were evaluated and 322 of those were enrolled in the study. A brief study design is depicted in Figure 1. Recipients who were on mTORi for at least 12 months were enrolled in mTORi arm. Recipients who did not have BKV and CMV real-time polymerase chain reaction (PCR) testing results and at least one allograft biopsy were excluded. Recipients who have CMV and/or BKV positivity, and/or CNI nephrotoxicity but had high immunological risk were not switched to mTORi and received various treatment protocols. Those were addressed in mTORi-free arm. Early mortalities (mortality within 3 months posttransplant) and recipients with primary nonfunction grafts were excluded.
Two groups were defined as follow;

- mTORi group: low-dose CNI (target: $2-4 \mathrm{ng} / \mathrm{dL}$ for tacrolimus and $25-50 \mathrm{ng} / \mathrm{mL}$ for cyclosporine-A) + mTORi (target: $5-7 \mathrm{ng} / \mathrm{dL}$ ); dose reductions were performed due to $\mathrm{CMV}$, BKV positivitity or $\mathrm{CNI}$ nephrotoxicity.

- mTORi-free group: standard dose CNI (target: 5-12 $\mathrm{mg} / \mathrm{dL})+\mathrm{MMF}$ (1-2 gr/day). Recipients who received mTORi less than 6 months also included in this group.

Allograft functions before the onset of mTORi, 1 and, 3-year allograft functions, and allograft losses were evaluated. CMV and BKV viremias were investigated in blood samples, by using reverse transcriptase quantitative PCR. Biopsy-proven AR episodes, donors' and recipients' ages were noted.

Ethics committee approval was obtained from "The University Scientific Research and Ethic Committe" of the Yeni Yuzyil University with IRB; 2020/06-478.

\section{Statistical Analysis}

Data were analyzed by using the Statistical Package for Social Sciences (S.P.S.S.) for Windows version 15. Numeric variables were presented as mean \pm standard deviation, and median (minimum and maximum). Categorical variables compared by using the Chi-Square test. Parametric variables were compared among the two groups, by using independent samples T-test. Allograft and patient survival rates were analyzed by Kaplan Meier survival curves. Cox-regression was used to demonstrate the impact of the potential factors on recipient and allograft survival. $\mathrm{p}<0.05$ was accepted significant in a $95 \%$ confidence interval.

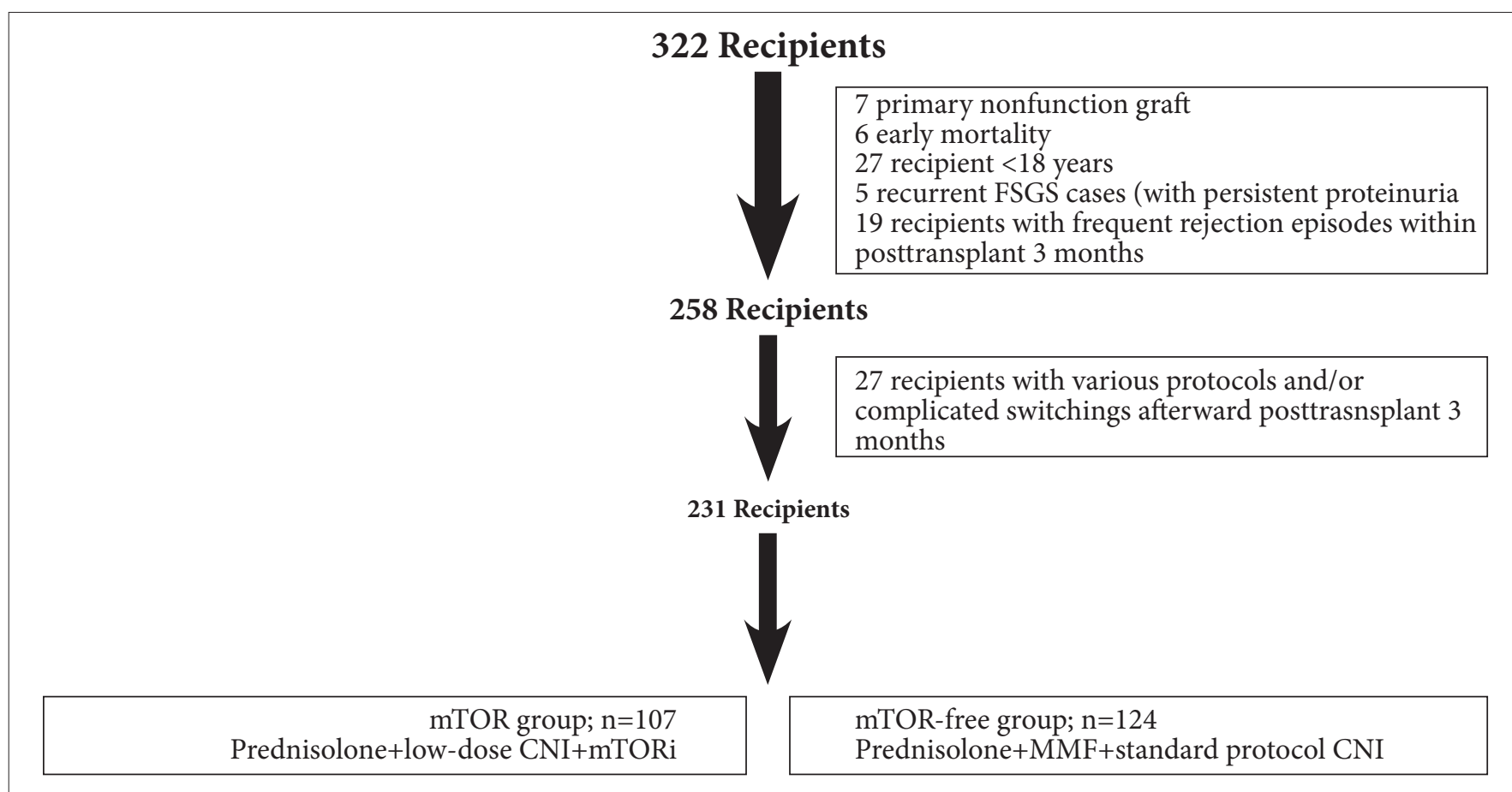

Figure 1. The recipient and allograft survival rates of two groups. 


\section{RESULTS}

A total of 231 recipients, 132 males, and 99 females were evaluated, and the mean age was $45.79 \pm 11.10$. One hundredseven recipients received mTORi and 124 recipients received mTORi-free protocol. Table 1 demonstrates the clinical and laboratory features of recipients and donors. $83.9 \%$ of the allograft donation was from living donors. $32.9 \%$ of recipients experienced at least one AR episode. The average follow-up duration was $54.82 \pm 20.23$ months.

In mTORi arm, CMV and BKV infections and AR episodes were in higher rate compared to mTORi-free $\operatorname{arm}(\mathrm{p}=0.001$ for all). $89.1 \%$ of CMV and $89.5 \%$ of BKV viremias were in mTORi arm. 1 and 3-year allograft functions (eGFR) were worse in mTORi arm ( $\mathrm{p}=0.001$ and $\mathrm{p}=0.001$, respectively) (Table 2). eGFR before switching to $\mathrm{mTORi}$ was $57.28 \pm 22.17$ $\mathrm{ml} / \mathrm{dk} / 1.73 \mathrm{~m} 2$ and was similar to the 12 -month and 36-month eGFR, $\mathrm{p}=0.37$ and $\mathrm{p}=0.11$, respectively.

Allograft survival rates were similar in mTORi and mTORifree arms at posttransplant 1 and 3 -year $(\mathrm{p}=0.52$ and $\mathrm{p}=0.72$, respectively) (Figure 2). Cox-regression analysis demonstrated CMV and BKV viremia positivities had no impact on 1 and 3-year allograft survival rates $(\mathrm{p}=0.525$ and $\mathrm{p}=0.876, \mathrm{p}=0.982$ and $\mathrm{p}=0.905$ ) (Table 3). Besides AR episodes had a negative impact on 3-year allograft survival $(\mathrm{p}=0.014$ and $\mathrm{OR}=3.996)$. Donor age had an impact both in 1 and 3 -year allograft survival rates $(\mathrm{p}=0.022$ and $\mathrm{OR}=1.039$, and $\mathrm{p}=0.001$ and $\mathrm{OR}=1.055$ ).
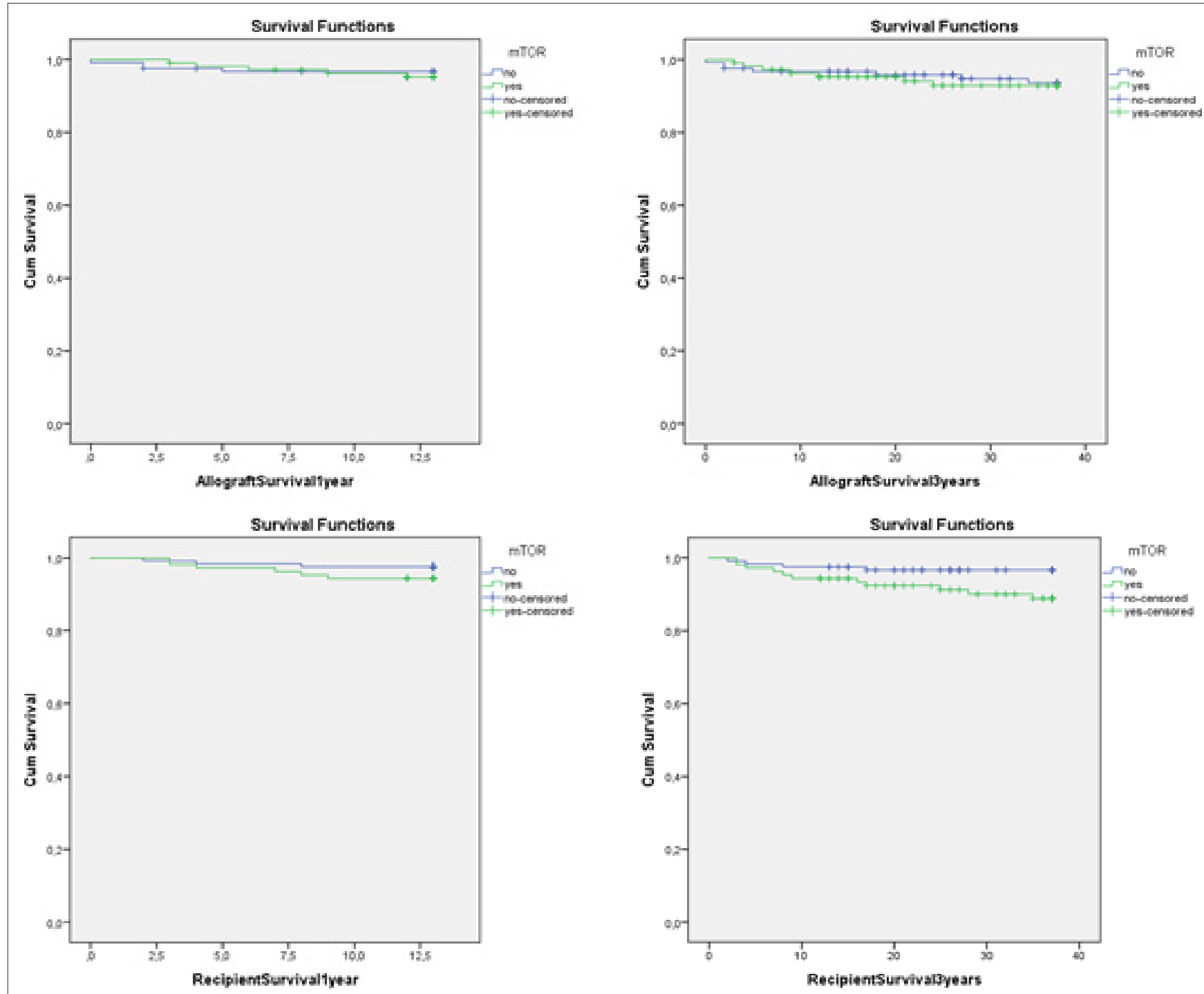

\begin{tabular}{|c|c|c|c|}
\hline & mTORi & mTORi-free & P value \\
\hline Recipient survival rate; & $94.3 \%$ & $97.5 \%$ & 0.23 \\
1 year & $89.6 \%$ & $96.6 \%$ & 0.06 \\
\hline 3 years & & & \\
Allograft survival rate; $\quad$ year & $92.3 \%$ & $96.6 \%$ & 0.52 \\
3 years & $90.4 \%$ & $94.1 \%$ & 0.72 \\
\hline
\end{tabular}

Figure 2. Study design and case selection

FSGS; focal segmental glomerulosclerosis, mTOR; mammalian target of rapamycine, CNI; calcineurin inhibitör. 
Table 1. Clinical and laboratory features of recipients and donors.

\begin{tabular}{|lc|}
\hline & $\mathbf{N}=\mathbf{2 3 1}$ \\
\hline Male/female & $132 / 99$ \\
Age, year & $45.79 \pm 11.10$ \\
Recipient BMI, $\mathrm{kg} / \mathrm{m}^{2}$ & $24.06 \pm 4.24$ \\
Donor BMI, $\mathrm{kg} / \mathrm{m}^{2}$ & $26.20 \pm 4.15$ \\
Donor type; living/deceased & $194(83.9 \%) / 37(16.1 \%)$ \\
BKV positivity, yes/no & $48(20.7 \%) / 183(79.3 \%)$ \\
CMV positivity, yes/no & $46(19.9 \%) / 185(80.1 \%)$ \\
Acute rejection, yes/no & $76(32.9 \%) / 155(67.1 \%)$ \\
Average allograft survival, month (5-year) & $47.36 \pm 24.03$ \\
Average recipient survival, month (5-year) & $52.82 \pm 20.23$ \\
eGFR, ml/dk/min/1.73m ${ }^{2} ;$ & \\
3 months & $62.38 \pm 33.26$ \\
1 year & $71.21 \pm 24.87$ \\
3 years & $63.06 \pm 24.09$ \\
5 years & $59.28 \pm 26.43$ \\
Recipient survival rate; & \\
1 year & $96.0 \%$ \\
3 years & $93.3 \%$ \\
5 years & $91.2 \%$ \\
Allograft survival rate; & \\
1 year & $96.0 \%$ \\
3 years & $93.8 \%$ \\
years & $91.1 \%$ \\
\hline BMI; body mass index, BKV; polyoma B-K virus, CMV; cytomegalovirus, eGFR; \\
estimated glomerular filtration rate.
\end{tabular}

\begin{tabular}{|c|c|c|c|}
\hline & $\begin{array}{c}\text { mTORi; } \\
\text { n=107 }\end{array}$ & $\begin{array}{c}\text { mTORi-free; } \\
\mathbf{n}=124\end{array}$ & $\begin{array}{c}P \\
\text { value }\end{array}$ \\
\hline Recipient age, year & $45.63 \pm 12.01$ & $44.86 \pm 10.20$ & 0.602 \\
\hline Male/female & $62 / 45$ & $74 / 50$ & 0.589 \\
\hline Recipient BMI, $\mathrm{kg} / \mathrm{m}^{2}$ & $23.75 \pm 3.92$ & $24.06 \pm 4.16$ & 0.662 \\
\hline $\begin{array}{l}\text { CMV positivity, } \\
\text { yes/no }\end{array}$ & $\begin{array}{c}41 / 66 \\
(38.3 \% / 61.2 \%)\end{array}$ & $\begin{array}{c}5 / 119 \\
(4.0 \% / 96.0 \%)\end{array}$ & 0.001 \\
\hline $\begin{array}{l}\text { BKV positivity, } \\
\text { yes/no }\end{array}$ & $\begin{array}{c}43 / 64 \\
(40.1 \% / 59.9 \%)\end{array}$ & $\begin{array}{c}5 / 119 \\
(4.0 \% / 96.0 \%)\end{array}$ & 0.001 \\
\hline $\begin{array}{l}\text { Acute rejection, } \\
\text { yes/no }\end{array}$ & $\begin{array}{c}40 / 67 \\
(37.38 \% / 62.62 \%)\end{array}$ & $\begin{array}{c}22 / 102 \\
(17.7 \% / 82.3 \%)\end{array}$ & 0.001 \\
\hline $\begin{array}{l}\text { CNI induced } \\
\text { nephrotoxicity (biopsy } \\
\text { proven); yes/no }\end{array}$ & $28.6 \% / 71.4 \%$ & $17.4 \% / 78.6 \%$ & 0.603 \\
\hline $\begin{array}{l}\text { eGFR, } \mathrm{ml} / \mathrm{dk} / 1.73 \mathrm{~m}^{2} \text {; } \\
1 \text { year } \\
3 \text { years }\end{array}$ & $\begin{array}{l}59.36 \pm 25.69 \\
54.41 \pm 23.21\end{array}$ & $\begin{array}{l}71.85 \pm 25.72 \\
70.96 \pm 27.00\end{array}$ & $\begin{array}{l}0.001 \\
0.001\end{array}$ \\
\hline $\begin{array}{l}\text { Immunological risk } \\
\text { assessment } \\
\text { Low risk } \\
\text { High risk }\end{array}$ & $\begin{array}{l}82.4 \% \\
17.6 \%\end{array}$ & $\begin{array}{l}77.0 \% \\
23.0 \%\end{array}$ & 0.751 \\
\hline $\begin{array}{l}\text { CNI induced } \\
\text { nephrotoxicity } \\
\text { Yes } \\
\text { No }\end{array}$ & $\begin{array}{l}28.6 \% \\
71.4 \%\end{array}$ & $\begin{array}{l}17.4 \% \\
82.6 \%\end{array}$ & 0.603 \\
\hline
\end{tabular}

The one and 3-year recipient survival rates were similar in the two groups $(p=0.23$ and $p=0.06)$ (Figure 2). Cox-regression analysis demonstrated CMV and BKV infections and AR episodes had no impact on 1 and 3-year recipient survival rates $(\mathrm{p}=0.235$ and $\mathrm{p}=0.872, \mathrm{p}=0.202$ and $\mathrm{p}=0.593$, and $\mathrm{p}=0.559$ and $\mathrm{p}=0.943$, respectively). However, recipient age was associated with worse 1 and 3 -year recipients survival rates $(\mathrm{p}=0.010$ and $\mathrm{OR}=1.094$, and $\mathrm{p}=0.001$ and $\mathrm{OR}=1.096$, respectively).

Subgroup analysis revealed that 3-month posttransplant eGFRs were similar in mTORi and mTORi-free $\operatorname{arm}, 63.44 \pm 32.16$ vs $61.18 \pm 29.15, p=0.10$. However, in mTORi arm, eGFR at the switching time was lower compared to eGFR at posttransplant 3-month, 63.44 \pm 32.16 vs57.28 $\pm 22.17, \mathrm{p}=0.04$. eGFR at 1 and 3 years posttransplant in recipients with $\mathrm{CMV}$ and/or BKV positivity and AR episodes are compared in Table 4. 3-year eGFR was worst in CMV viremia positive recipients compared to the CMV viremia negative individuals $(\mathrm{p}=0.005)$ (Table 4$)$. AR rates in $\mathrm{CMV}$ and $\mathrm{BKV}$ viremia positive recipients were given in Table 5.

Table 4. Estimated glomerular filtration rates at posttransplant 3 , 12 , and 36 months in CMV, BKV viremia positive recipients and in recipients with AR episodes.

\begin{tabular}{|lccc|}
\hline & $\begin{array}{c}\text { 3-month } \\
\text { posttransplant eGFR }\end{array}$ & $\begin{array}{c}\text { 1-year } \\
\text { eGFR }\end{array}$ & $\begin{array}{c}\text { 3-year } \\
\text { eGFR }\end{array}$ \\
\hline CMV; & & & \\
Negative & $67.39 \pm 26.65$ & $71.47 \pm 24.57$ & $70.22 \pm 22.42$ \\
Positive & $59.37 \pm 28.81$ & $65.21 \pm 25.92$ & $\begin{array}{c}40.40 \pm 13.95 \\
\text { p }=\mathbf{0 . 0 0 5}\end{array}$ \\
& $\mathrm{p}=0.08$ & $\mathrm{p}=0.19$ & \\
BKV; & & & \\
Negative & $65.45 \pm 27.53$ & $70.93 \pm 25.29$ & $64.31 \pm 25.30$ \\
Positive & $72.49 \pm 19.18$ & $69.19 \pm 18.58$ & $\begin{array}{c}58.08 \pm 20.11 \\
\text { p }\end{array}$ \\
AR; & $\mathrm{p}=0.11$ & $\mathrm{p}=0.68$ & $\mathrm{p}=0.61$ \\
No & $67.91 \pm 24.99$ & $70.68 \pm 23.10$ & $\begin{array}{c}67.89 \pm 23.46 \\
\text { Yes }\end{array}$ \\
& $60.59 \pm 31.45$ & $67.33 \pm 25.11$ & $49.88 \pm 25.22$ \\
$\mathrm{p}=0.06$ & $\mathrm{p}=0.38$ & $\mathrm{p}=0.11$ \\
\hline
\end{tabular}

Table 5. Acute rejection and calcineurin inhibitör nephrotoxicity in $\mathrm{CMV}$ and $\mathrm{BKV}$ infections

\begin{tabular}{|lccc|}
\hline & $\begin{array}{c}\text { Acute rejection } \\
\text { rates }^{\mathrm{a}}\end{array}$ & $\begin{array}{c}\text { CNI } \\
\text { nephrotoxicity }^{\mathrm{b}}\end{array}$ & p value \\
\hline $\begin{array}{l}\text { CMV; positive/ } \\
\text { negative }\end{array}$ & $18.5 \% / 11.0 \%$ & $17.4 \% / 28.6 \%$ & $0.13^{\mathrm{a}}$, \\
$\begin{array}{l}\text { BKV; positive/ } \\
\text { negative }\end{array}$ & $18.4 \% / 7.2 \%$ & $12.5 \% / 22.7 \%$ & $0.60^{\mathrm{b}}$ \\
\hline
\end{tabular}

\begin{tabular}{|c|c|c|c|}
\hline & CMV & BKV & AR \\
\hline & \multicolumn{3}{|c|}{$\mathrm{p}$ value, $95 \% \mathrm{CI}$, and odds ratio } \\
\hline 1-year recipient survival & $0.235(0.533-13.083) 2.640$ & $0.202(0.061-1.809) 0.331$ & $0.559(0.126-3.068) 0.622$ \\
\hline 3-year recipient survival & $0.872(0.295-4.219) 1.116$ & $0.593(0.220-2.375) 0.723$ & $0.943(0.349-3.107) 1.041$ \\
\hline 1-year allograft survival & $0.525(0.298-10.696) 1.787$ & $0.982(0.164-5.865) 0.980$ & $0.080(0.865-13.136) 3.370$ \\
\hline 3-year allograft survival & $0.876(0.221-5.887) 1.140$ & $0.805(0.185-3.707) 0.828$ & $0.014(1.331-11.997) 3.996$ \\
\hline
\end{tabular}




\section{DISCUSSION}

Renal transplantation (RTx) is the favorable choice of treatment in end-stage kidney disease due to having better patient survival advantages. Additionally, a logical posttransplant immunosuppression therapy has vital importance, since the over-immunosuppression is related to serious life-threating infections, malignancies, and allograft toxicity whereas low-immunosuppression is related to a higher rate of allograft rejection episodes. Clinicians commonly are forced to CNI minimizing approaches, due to $\mathrm{BKV}$, CMV infections, and the existence of the evidence piece of the biopsy-proven CNI toxicity. In this study, we indicated switching to mTORi due to various compelling issues (CMV and $\mathrm{BKV}$ viremias and CNI toxicity) might have no adverse outcomes on allograft survival and function.

The evolution in immunosuppressants has advanced with the introduction of the CNI. CNIs have been associated with reduced AR rates over time, however, long-term allograft survival and function have not improved to a satisfactory extent $(13,14)$. It is thought that CNI induced acute and chronic nephrotoxicity might have some adverse impact on allograft survival and function $(14,15)$. CNI induced nephrotoxicity is at a high rate in RTx recipients, up to $94 \%$ (16). mTORi-involving immunosuppressant protocols have been used to avoid CNI induced nephrotoxicity (either CNI dose reduction or complete withdrawal of CNI). This approach carries the risk of higher AR episodes, however, the previous studies reported conflictive outcomes. Additionally, given the available studies which demonstrated antiviral activities of mTORi against BKV, make mTORi a good option in enhancing the immunosuppression modifications, both via allowing CNI dose reduction, and via its antiviral activity $(17,18)$. Additionally, as an important part of the overall immunosuppressant dose reduction in the treatment of CMV viremia, switching to mTORi may provide some benefits. In our study, mTORi arm substantially was consisted of cases with CMV and BKV viremias positivities. One and 3-year allograft survival rates were similar in mTORi and mTORi-free groups. However, in the surviving allografts 1 and 3-year, eGFRs were worse in mTORi groups. Higher prevalences of $\mathrm{CMV}, \mathrm{BKV}$, and $\mathrm{AR}$ rates all might have an overall impact on reduced eGFR, in mTORi group. Subgroup analysis revealed CMV has associated with reduced 3-year eGFR.

Allograft survival rate and function depend on various potential adverse factors such as CMV and BKV infection, and acute rejection episodes. CMV is one of the most important infectious causes associated with substantial morbidity and mortality after organ transplantation $(19,20)$. CMV prevalence has a great variation among RTx studies (ranging from 5\% to 100\%) due to different population serostatus, immunosuppression protocols, and testing methods $(21,22)$. Immunosuppression level is the most important influent on the development of $\mathrm{CMV}$ infection, and lowering immunosuppression along with valganciclovir/ganciclovir therapy is the main firstline approach in the disease control $(20,23-25)$. In our cohort, CMV prevalence is $19.9 \%$, and $89.1 \%$ of those were in mTOR group. 1-year eGFR in CMV positive and negative groups were similar. In CMV viremia positive recipients, after immunosuppression lowering and CMV disease treatment with valganciclovir/ganciclovir therapy, allograft function did not recovery at 3-year posttransplant (the worst eGFR). AR seems to have an impact on 3-year allograft functions. AR rate was higher in recipients with CMV viremia but statistically was not significant. However, the regression analysis revealed that AR episodes had an impact on the 3-year allograft survival in mTORi arm. CMV viremia and AR development are well-known and interrelated issues in RTx $(26,27)$. However, allograft survival rates were at 1 and 3-year were similar in mTORi and mTORi-free groups, and surprisingly, CMV viremia positivity had no impact on allograft survival in our cohort. We think this preferable outcome might be associated with mTORi use and less CNI induced nephrotoxicity (biopsy-proven $\mathrm{CNI}$ nephrotoxicity has been found less in CMV positive recipients) (17.4\% vs 28.6\%). Posttransplant 1 and 3 -year recipients' survival rates were also similar in both groups, and CMV viremia existence had no impact on the recipient survival.

Polyoma B-K virus (BKV) is highly prevalent in the general population with over $80 \%$ of individuals having serological positivities against BKV $(28,29)$. BKV reactivation is a common problem after therapeutic immunosuppression in RTx. BKV viremia occurs in up to $13 \%$ of RTx and BKV associated nephropathy prevalence is approximately $10 \%(30-32)$ The prolonged persistent $\mathrm{BK}$ viremia is associated with the development of ClassII donor-specific antibodies and higher AR rates $(33,34)$. BKV nephropathy has been associated with reduced 3-year overall allograft survival (35). The immunosuppression level is the main promotor factor in the development of BK viremia, and lowering immunosuppression (dose adjustment, drug withdrawal, substituting with another drug) is the key point of the treatment (36). In our cohort, BKV prevalence is $20.7 \%$, and $89.5 \%$ of the cases were in mTORi arm. One and 3-year allograft and recipient survival rates were similar among BKV viremia positive and negative recipients. Cox-regression analysis revealed that BKV had no impact on overall allograft and recipient survival. AR rates were found higher in BKV positive recipients, as previous studies reported. 


\section{CONCLUSION}

The low-dose CNI + mTORi protocol which is established due to many mandatory factors, has not worse outcomes compared to the protocols involving standard dose CNI.

Limitations of the study; the treatments of CMV and $\mathrm{BKV}$ infections and AR episodes and the impacts of the success or failure of those treatment protocols were not included in the study. Additionally, lacking assessment of the induction protocols, of the immunological risk, and of the adverse drug reactions were some other limitations of the study.

\section{ETHICAL DECLARATIONS}

Ethics Committee Approval: The University Scientific Research and Ethic Committe of the Yeni Yuzyil University; 2020/06-478.

Informed Consent: Because the study was designed retrospectively, no written informed consent form was obtained from patients.

Referee Evaluation Process: Externally peer-reviewed.

Conflict of Interest Statement: The authors have no conflicts of interest to declare.

Financial Disclosure: The authors declared that this study has received no financial support.

Author Contributions: Mehmet Emin Demir: Project designer, writer, coordianator, Ozgur Merhametsiz: Data collection, Murat Sevmis: Statistical analyzes, Murathan Uyar: Advisor, Sema Aktas: Advisor, Sinasi Sevmis: Advisor

\section{REFERENCES}

1. Kajiwara M, Masuda S. Role of mTOR Inhibitors in Kidney Disease. Int J Mol Sci 2016 Jun 21; 17: 975.

2. Badve SV, Pascoe EM, Burke M, et al. Mammalian target of rapamycin inhibitors and clinical outcomes in adult kidney transplant recipients. Clin J Am Soc Nephrol 2016; 11: 1845-55.

3. Farouk SS, Rein JL. The many faces of calcineurin inhibitor toxicity-what the FK? Adv Chronic Kidney Dis 2020; 27: 56-66.

4. Nankivell BJ, Borrows RJ, Fung CL, O'Connell PJ, Allen RD, Chapman JR. The natural history of chronic allograft nephropathy. N Engl J Med 2003; 349: 2326-33.

5. Prashar R, Venkat KK. Immunosuppression minimization and avoidance protocols: when less is not more. Adv Chronic Kidney Dis 2016; 23: 295-300.

6. Farkas SA, Schnitzbauer AA, Kirchner G, Obed A, Banas B, Schlitt HJ. Calcineurin inhibitor minimization protocols in liver transplantation. Transpl Int 2009; 22: 49-60.

7. Rostaing L, Wéclawiak H, Mengelle C, Kamar N. Viral infections after kidney transplantation. Minerva Urol Nefrol 2011; 63: 59-71.

8. Malvezzi P, Jouve T, Rostaing L. Negative impact of CMV and BKV infections on kidney-allograft function at 1-year post-transplantation: can it be changed by modifying immunosuppression? EBioMedicine 2018; 34: 2-3.
9. Tedesco-Silva H, Felipe C, Ferreira A, et al. Reduced incidence of cytomegalovirus infection in kidney transplant recipients receiving everolimus and reduced tacrolimus doses. Am J Transplant 2015; 15: 2655-64.

10. Jouve T, Rostaing L, Malvezzi P. Place of mTOR inhibitors in management of BKV infection after kidney transplantation. J Nephropathol 2016; 5: 1-7.

11. Malvezzi P, Rostaing L. Renal transplantation in 2016: Novel approaches to improve recipient and allograft outcomes. Nat Rev Nephrol 2017; 13: 73-74.

12.Sawinski D, Trofe-Clark J, Leas B, et al. Calcineurin inhibitor minimization, conversion, withdrawal, and avoidance strategies in renal transplantation: a systematic review and meta-analysis. Am J Transplant 2016; 16: 2117-38.

13. Meier-Kriesche HU, Schold JD, Srinivas TR, Kaplan B. Lack of improvement in renal allograft survival despite a marked decrease in acute rejection rates over the most recent era. Am J Transplant 2004; 4: 378-83.

14. Tantravahi J, Womer KL, Kaplan B. Why hasn't eliminating acute rejection improved graft survival? Annu Rev Med 2007; 58: 369 85 .

15. Naesens M, Kuypers DR, Sarwal M. Calcineurin inhibitor nephrotoxicity. Clin J Am Soc Nephrol 2009; 4: 481-508.

16.Zununi Vahed S, Ardalan M, SamadiN, Omidi Y. Pharmacogenetics and drug-induced nephrotoxicity in renal transplant recipients. Bioimpacts 2015; 5: 45-54.

17. Moscarelli L, Caroti L, Antognoli G, et al. Everolimus leads to a lower risk of BKV viremia than mycophenolic acid in de novo renal transplantation patients: a single-center experience. Clin Transplant 2013; 27: 546-54.

18. Hirsch HH, Yakhontova K, Lu M, Manzetti J. BK polyomavirus replication in renal tubular epithelial cells is inhibited by Sirolimus, but activated by tacrolimus through a pathway involving FKBP12. Am J Transplant 2016; 16: 821-32.

19. Ramanan P, Razonable RR. Cytomegalovirus infections in solid organ transplantation: a review. Infect Chemother 2013; 45: 26071.

20. Selvey LA, Lim WH, Boan P, et al. Cytomegalovirus viraemia and mortality in renal transplant recipients in the era of antiviral prophylaxis. Lessons from the western Australian experience. BMC Infect Dis 2017; 17: 501.

21. Cordero E, Casasola C, Ecarma R, Danguilan R. Cytomegalovirus disease in kidney transplant recipients: incidence, clinical profile, and risk factors. Transplant Proc 2012; 44: 694-700.

22.Durlik M, Siennicka J, Litwińska B, et al. Clinical manifestations and diagnosis of cytomegalovirus infection in renal allograft recipients. Transplant Proc 2001; 33: 1237-9.

23. Avery RK. Low-dose valganciclovir for cytomegalovirus prophylaxis in organ transplantation: is less really more? Clin Infect Dis 2011; 52: 322-4.

24. Asberg A, Jardine AG, Bignamini AA, et al. VICTOR Study Group. Effects of the intensity of immunosuppressive therapy on outcome of treatment for CMV disease in organ transplant recipients. Am J Transplant 2010; 10: 1881-8.

25. Anglicheau D, Lautrette A, Scieux C, Flamant M, Morinet F, Legendre C. Efficacy and safety of lowering immunosuppression to treat $\mathrm{CMV}$ infection in renal transplant recipients on valaciclovir prophylaxis: a pilot study. Nephrol Dial Transplant 2003; 18: 1654-6.

26. Hasanzamani B, Hami M, Zolfaghari V, Torkamani M, Ghorban Sabagh M, Ahmadi Simab S. The effect of cytomegalovirus infection on acute rejection in kidney transplanted patients. J Renal Inj Prev 2016; 5: 85-8. 
27.Sagedal S, Nordal KP, Hartmann A, et al. The impact of cytomegalovirus infection and disease on rejection episodes in renal allograft recipients. Am J Transplant 2002; 2: 850-6.

28. Stolt A, Sasnauskas K, Koskela P, Lehtinen M, Dillner J. Seroepidemiology of the human polyomaviruses. J Gen Virol 2003; 84: 1499-504.

29. Knowles WA. Discovery and epidemiology of the human polyomaviruses $\mathrm{BK}$ virus (BKV) and JC virus (JCV). Adv Exp Med Biol 2006; 577: 19-45.

30. Hirsch HH, Knowles W, Dickenmann M, et al. Prospective study of polyomavirus type BK replication and nephropathy in renaltransplant recipients. N Engl J Med 2002; 347: 488-96.

31.Brennan DC, Agha I, Bohl DL, et al. Incidence of BK with tacrolimus versus cyclosporine and impact of preemptive immunosuppression reduction. Am J Transplant 2005; 5: 582-94.

32. Hirsch HH. BK virus: opportunity makes a pathogen. Clin Infect Dis 2005; 41: 354-60.

33. Sawinski D, Forde KA, Trofe-Clark J, et al. Persistent BK viremia does not increase intermediate-term graft loss but is associated with de novo donor-specific antibodies. J Am Soc Nephrol 2015; 26: 966-75.

34. Haas M, Loupy A, Lefaucheur C, et al. The Banff 2017 Kidney Meeting Report: Revised diagnostic criteria for chronic active $\mathrm{T}$ cell-mediated rejection, antibody-mediated rejection, and prospects for integrative endpoints for next-generation clinical trials. Am J Transplant 2018; 18: 293-307.

35. Schold JD, Rehman S, Kayle LK, Magliocca J, Srinivas TR, MeierKriesche HU. Treatment for BK virus: incidence, risk factors and outcomes for kidney transplant recipients in the United States. Transpl Int 2009; 22: 626-34.

36. Sawinski D, Goral S. BK virus infection: an update on diagnosis and treatment. Nephrol Dial Transplant 2015; 30: 209-17. 